\title{
Antimicrobial Activity of Amino Acid-Capped Zinc and Copper Sulphide Nanoparticles
}

\author{
Thapelo P. Mofokeng, ${ }^{1}$ Makwena J. Moloto ${ }^{1},{ }^{1}$ Poslet M. Shumbula, ${ }^{2}$ \\ Pardon Nyamukamba, ${ }^{1}$ Pierre K. Mubiayi ${ }^{D},{ }^{1}$ Samkeliso Takaidza, ${ }^{3}$ and Laurette Marais ${ }^{3}$ \\ ${ }^{1}$ Department of Chemistry, Vaal University of Technology, Private Bag X021, Vanderbijlpark 1900, South Africa \\ ${ }^{2}$ Advanced Materials Division, Mintek, Private Bag X3015, Randburg 2125, South Africa \\ ${ }^{3}$ Department of Biotechnology, Vaal University of Technology, Private Bag X021, Vanderbijlpark 1900, South Africa
}

Correspondence should be addressed to Makwena J. Moloto; makwenam@vut.ac.za

Received 23 April 2018; Revised 7 June 2018; Accepted 21 June 2018; Published 1 August 2018

Academic Editor: Paresh Chandra Ray

Copyright (c) 2018 Thapelo P. Mofokeng et al. This is an open access article distributed under the Creative Commons Attribution License, which permits unrestricted use, distribution, and reproduction in any medium, provided the original work is properly cited.

\begin{abstract}
The synthesis of polydispersed zinc sulphide and copper sulphide nanocrystals capped with polar L-alanine (Aln) and L-aspartic acid (Asp) molecules is reported. The resulting nanocrystals were characterized by UV-visible spectroscopy (UV-Vis), photoluminescence (PL), X-ray diffraction (XRD), transmission electron microscopy (TEM), and Fourier transform infrared spectroscopy (FT-IR). UV-Vis absorption spectra of all samples were blue-shifted from the bulk band edges due to quantum confinement effects. PL emission spectrum of the nanoparticles showed peaks at 453 and $433 \mathrm{~nm}$ for Aln-capped ZnS and CuS nanoparticles, respectively, while peaks for Asp-capped $\mathrm{ZnS}$ and $\mathrm{CuS}$ nanoparticles were observed at 455 and $367 \mathrm{~nm}$, respectively. The average particle sizes for Aln-capped $\mathrm{ZnS}$ and Asp-capped $\mathrm{ZnS}$ nanoparticles synthesized at $35^{\circ} \mathrm{C}$ were measured to be $2.88 \mathrm{~nm}$ and $1.23 \mathrm{~nm}$, respectively. The antibacterial properties were tested using different strains of both positive and negative bacteria and fungi. It was found that capped-copper sulphide nanoparticles were more effective against the bacteria than cappedzinc sulphide nanoparticles. Staphylococcus aureus (ATCC 25923) was the most susceptible one with an MIC of $0.05 \mathrm{mg} / \mathrm{mL}$ for uncapped-CuS nanoparticles while Pseudomonas aeruginosa (ATCC 15442) and Cryptococcus neoformans (ATCC 14116) were the least ones with the MIC of $3.125 \mathrm{mg} / \mathrm{mL}$ for both uncapped-CuS and Aln-capped CuS.
\end{abstract}

\section{Introduction}

In the past decade, there has been an increase in the field of synthesis of nanoparticles with controlled morphologies. The synthesis of metal chalcogenide nanoparticles, in particular, has become an area of interest due to their sizedependent unique properties which include chemical, physical, magnetic, electronic, and surface properties which are different from the bulk properties [1]. Among the metal chalcogenides, zinc sulphide $(\mathrm{ZnS})$ and copper sulphide $(\mathrm{CuS})$ have attracted much research interest due to their numerous potential applications. $\mathrm{ZnS}$ has been widely studied due to its appealing electronic properties such as wide optical band gap and high exciton binding energy, rendering it to be very attractive material for optical application especially in nanocrystalline form [2,3]. CuS has also been widely studied, with the particles finding more attention due to their low toxicity. Some of the reported potential applications of metal chalcogenides include medical, catalysis, electrochemistry, biotechnology, trace substance detection, biomedical, biosensor, catalyst for bacterial biotoxin elimination, and lower-cost electrode [4-10]. Copper sulphides such as $\mathrm{CuS}$ (covellite), $\mathrm{Cu}_{1.75} \mathrm{~S}$ (anilite), $\mathrm{Cu}_{1.8} \mathrm{~S}$ (digenite), $\mathrm{Cu}_{1.95} \mathrm{~S}$ (djurlite), and $\mathrm{Cu}_{2} \mathrm{~S}$ are of great interest as they can be applied in energy storage, owing to their variations in stoichiometric compositions, complex structures, and valence states [11]. CuS phase exists in two forms, the amorphous brown chalcocite $\mathrm{CuS}$ and green crystalline covellite [12]. The optical properties of copper chalcogenides greatly depend on the copper vacancies [13]. 
Zinc sulphide also exists in two main crystalline forms: the more stable cubic form zinc blende with a band gap of 3.5-3.7 eV and the hexagonal form wurtzite with a band gap of $3.7-3.8 \mathrm{eV}$ [14].

Although several applications of $\mathrm{ZnS}$ and $\mathrm{CuS}$ nanoparticles have been reported, their use as antimicrobial agents is becoming important due to the lifethreatening and growing antibiotic resistance which is a public concern in health and food technology sectors. The advent of nanotechnology led to the development of nanomaterials which have a high surface-to-volume ratio which increases their interaction with microorganisms. Several chalcogenides such as $\mathrm{CdS}, \mathrm{CdSe}$, and $\mathrm{PbS}$ have been used in the past as antimicrobial agents, but $\mathrm{CuS}$ is preferred due to its low cost and less hazardous nature [15]. Highly ordered ZnS nanocrystals with uniform particle size, shape, and good optical properties have also been used for biomedical applications [16]. Different preparation methods such as microemulsion $[17,18]$, hot injection [16], electrophoresis deposition [19] and sol-gel [11], and chemical method [20] were explored in the past decade for synthesizing chalcogenide nanoparticles. However, chemical method is still the most widely used because it allows better control of sizes, shapes, and functionalization [21]. In this study, an environmentally benign colloidal method was used to prepare alanine and aspartic acid-capped copper sulphide and zinc sulphide nanoparticles, with thioacetamide (TAA) as the sulphur source. The nanoparticles were assessed for their antibacterial properties against different strains of bacteria and fungi.

\section{Experimental}

2.1. Materials. Zinc chloride, copper chloride, L-alanine (Aln), L-aspartic acid (Asp), sodium hydroxide, thioacetamide (TAA), acetone, amphotericin $\mathrm{B}$, and neomycin were purchased from Sigma-Aldrich and used without any further purification. Distilled water was used in all preparations of solutions.

2.2. Synthesis of Metal Sulphide Nanoparticles. The nanoparticles were synthesized using a modified method described by Tan et al. [22]. Typically, $2.0 \mathrm{~g}$ of amino acid (Aln or Asp) was dissolved in $30 \mathrm{~cm}^{3}$ of distilled water while stirring at room temperature. An aqueous metal chloride $\left(\mathrm{ZnCl}_{2}\right.$ or $\left.\mathrm{CuCl}_{2}\right)$ solution $\left(5 \mathrm{~cm}^{3}\right.$ of $\left.0.744 \mathrm{M}\right)$ was then added to the amino acid solution, and the $\mathrm{pH}$ of the mixture was adjusted to 10 using aqueous sodium hydroxide $(1 \mathrm{M})$. Aqueous thioacetamide $\left(5 \mathrm{~cm}^{3}\right.$ of $\left.1.33 \mathrm{M}\right)$ was then added to the mixture. The temperature of the mixture was allowed to stabilize at $35^{\circ} \mathrm{C}$ and continued to run for 1 hour with vigorous stirring under nitrogen atmosphere. Upon reaction completion, the mixture was allowed to cool to room temperature, and the precipitates were isolated by centrifugation. The nanoparticles were washed several times with acetone and left overnight at room temperature to dry in a fume hood.
2.3. Antimicrobial Studies: Selected Microorganisms. Staphylococcus aureus (ATCC 25923), E. faecalis (ATCC 29212), Klebsiella pneumoniae (NCTC 9633), Pseudomonas aeruginosa (ATCC 15442), Candida albicans (ATCC 14053), and Cryptococcus neoformans (ATCC 14116).

2.4. Antibacterial Activity. Minimum inhibitory concentrations (MICs) of the nanoparticles were determined using the microdilution bioassay as described by Eloff [23]. In a typical experiment, overnight cultures of two Gram-positive (Staphylococcus aureus ATCC 25923 and E. faecalis ATCC 29212) and two Gram-negative (Klebsiella pneumoniae ATCC 13883 and Pseudomonas aeruginosa ATCC 15442) bacterial strains were diluted with sterile Mueller-Hinton $(\mathrm{MH})$ broth to give final inoculums of approximately $10^{6} \mathrm{CFU} / \mathrm{mL}$. The nanoparticles were suspended in distilled water to give a concentration of $12.5 \mathrm{mg} / \mathrm{mL}$. $100 \mu \mathrm{L}$ of each nanoparticle solution was serially diluted twofold with sterile distilled water in a 96-well microtiter plate for each of the four bacterial strains. A twofold dilution of neomycin $(0.1 \mathrm{mg} / \mathrm{mL})$ was used as a positive control against each bacterium. $100 \mu \mathrm{L}$ of each bacterial culture was added to each well and the resazurin indicator was added in each well. Water and broth were included as negative controls. The plates were covered with lids and incubated at $37^{\circ} \mathrm{C}$ for $24 \mathrm{~h}$ [24]. Wells with bacterial growth were indicated by the colour change observed from purple to pink or colourless. The lowest concentration of nanoparticles at which no colour change occurred was recorded as the MIC value. All the experiments were performed in triplicate.

2.5. Antifungal Activity. A microdilution method as described by Eloff [23] and modified for fungi by Masoko et al. [25] was used to determine the antifungal activity against Candida albicans (ATCC 14053) and Cryptococcus neoformans (ATCC 14116). In a typical experiment, an overnight fungal culture was prepared in yeast malt (YM) broth. $400 \mu \mathrm{L}$ of the overnight culture was added to $4 \mathrm{~mL}$ of sterile saline, and absorbance was read at $530 \mathrm{~nm}$. The absorbance was adjusted with sterile saline to match that of a $0.5 \mathrm{M}$ McFarland standard solution. From this standardised fungal stock, a $1: 1000$ dilution with sterile YM broth was prepared to give a final inoculum of approximately $10^{6} \mathrm{CFU} / \mathrm{mL}$. The nanoparticles were suspended in distilled water to give a concentration of $12.5 \mathrm{mg} / \mathrm{mL} .100 \mu \mathrm{L}$ of each nanoparticle solution was serially diluted twofold with sterile distilled water in a 96-well microtitre plate. A similar twofold dilution of amphotericin B $(2.5 \mathrm{mg} / \mathrm{mL})$ was used as the positive control while water was used as negative and solvent controls, respectively. $100 \mu \mathrm{L}$ of the diluted fungal culture was added to each well, and resazurin solution was used as an indicator. The plates were covered with lids and incubated at $37^{\circ} \mathrm{C}$ for $24 \mathrm{hrs}$. The lowest concentration of nanoparticles at which no colour change occurred was recorded as the minimal fungicidal concentration (MFC). All the experiments were performed in triplicate. The average values were calculated for the MFC of test material [24]. 


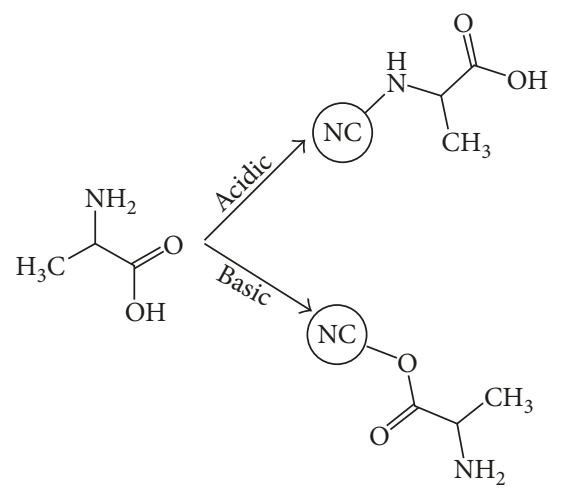

(a)

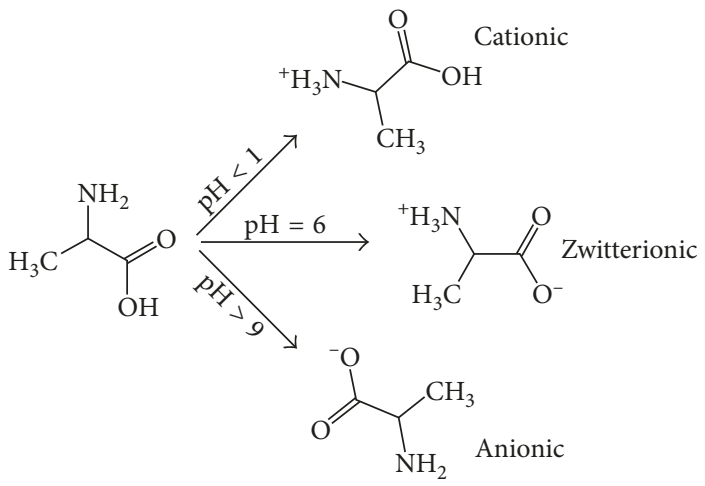

(b)

Scheme 1: Representation of the (a) binding motifs of L-alanine on the surface of copper sulphide nanoparticles and (b) effect of pH on $\mathrm{L}$-alanine in an aqueous medium.

2.6. Characterization. FTIR spectra were measured using Perkin Elmer Spectrum 400 FT-IR/FT-NIR spectrometer universal ATR with a diamond detector at a wavelength from $650 \mathrm{~cm}^{-1}$ to $4000 \mathrm{~cm}^{-1}$. The UV-Vis spectra of colloidal nanoparticle solutions were obtained using a Perkin Elmer Lambda $25 \mathrm{UV}$-Vis from 200 to $800 \mathrm{~nm}$ using distilled water as a reference solvent. The photoluminescence spectra of colloidal nanoparticle solutions were obtained using a Jasco spectrofluorometer FP-8600 from 200 to $800 \mathrm{~nm}$. The crystallographic characteristics of the nanoparticles were analysed by the XRD technique carried out on a Philips $X$ 'Pert materials research diffractometer using secondary graphite monochromated $\mathrm{Cu} \operatorname{K} \alpha$ radiation $(\lambda=1.5406 \AA)$ at $40 \mathrm{kV} / 50 \mathrm{~mA}$. Measurements were taken using a glancing angle of incidence detector at an angle of $2^{\circ}$, for $2 \theta$ values over $10^{\circ}-80^{\circ}$ in steps of $0.05^{\circ}$, with a scan speed of $0.01^{\circ} 2 \theta / \mathrm{s}$. The TEM images were obtained using a JEM-2100 F at $200 \mathrm{kV}$. The TEM grids were prepared by depositing a few drops of the solution obtained after centrifugation and allowed to dry in air.

\section{Results and Discussion}

3.1. FT-IR Spectroscopy. To understand the interaction between binding modes of pristine L-alanine and the prepared L-alanine-capped zinc and copper sulphide nanoparticles, FT-IR spectra were recorded. Figure 1(a), (A)-(C) shows the
FT-IR spectra of pristine L-alanine, L-alanine-capped $\mathrm{ZnS}$, and $\mathrm{CuS}$ nanoparticles at $\mathrm{pH}$ 10. Pristine L-alanine (Figure $1(\mathrm{a}),(\mathrm{A})$ ) has characteristic overlapping bands at 2500 and $3108 \mathrm{~cm}^{-1}$ which are assigned to $\mathrm{O}-\mathrm{H}$ and $\mathrm{N}-\mathrm{H}$ stretching, respectively. The L-alanine-capped $\mathrm{ZnS}$ spectrum (Figure 1(a), (B)) have a broad vibration band around $3253 \mathrm{~cm}^{-1}$ associated with $\mathrm{O}-\mathrm{H}$ stretching mode of water. The broad $\mathrm{N}-\mathrm{H}$ stretching mode around $1568 \mathrm{~cm}^{-1}$ is less intense compared to that of pristine L-alanine. This is as a result of the bonds that are strained due to bonding to the surface of nanocrystals. The peaks appearing in the finger print region, from 500 to $1000 \mathrm{~cm}^{-1}$, can be assigned to mixed banding modes of $\mathrm{C}-\mathrm{C}$ and $\mathrm{C}-\mathrm{O}$ moieties of the L-alanine-capped $\mathrm{ZnS}$ nanoparticles. The FTIR spectrum of L-alanine-capped $\mathrm{CuS}$ nanoparticles (Figure 1(a), (C)) depicts a vibrational band around $3250 \mathrm{~cm}^{-1}$ which is associated with the $\mathrm{N}-\mathrm{H}$ stretching frequency. This strongly suggests that $\mathrm{CuS}$ nanoparticles were capped with L-alanine through the negatively charged oxide moiety. The $\mathrm{N}-\mathrm{H}$ band of L-alanine-capped $\mathrm{CuS}$ nanoparticles was more noticeable compared to the pristine alanine because the bonds are constrained due to bonding to the surface of the nanoparticles. The other differences observed were on the $\mathrm{N}-\mathrm{H}\left(1593 \mathrm{~cm}^{-1}\right)$ and $\mathrm{C}-\mathrm{O}\left(1280 \mathrm{~cm}^{-1}\right)$ and bands which shifted to higher frequencies compared to the pristine alanine. These differences arise from the electron cloud being evenly distributed around the $\mathrm{O}-\mathrm{C}-\mathrm{O}$ moiety, 


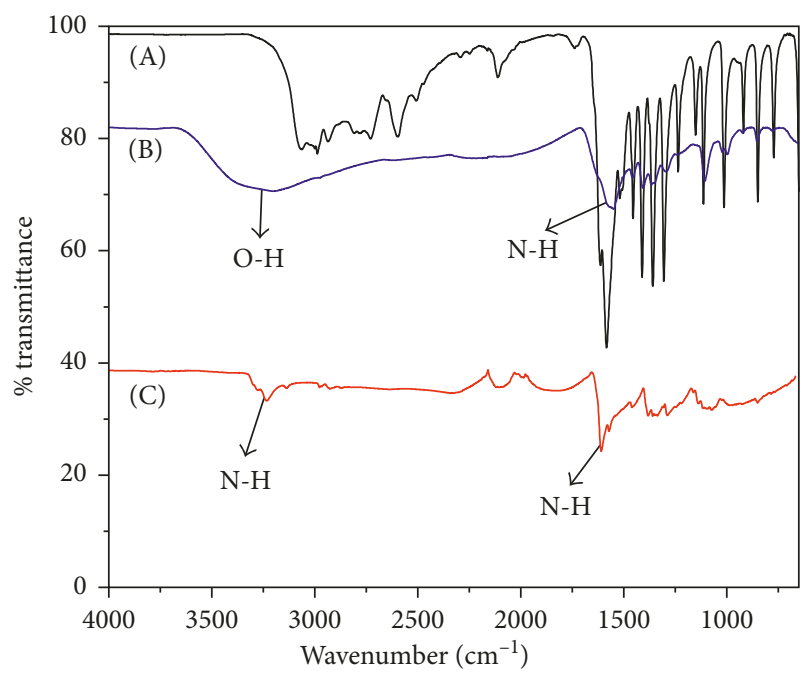

(a)

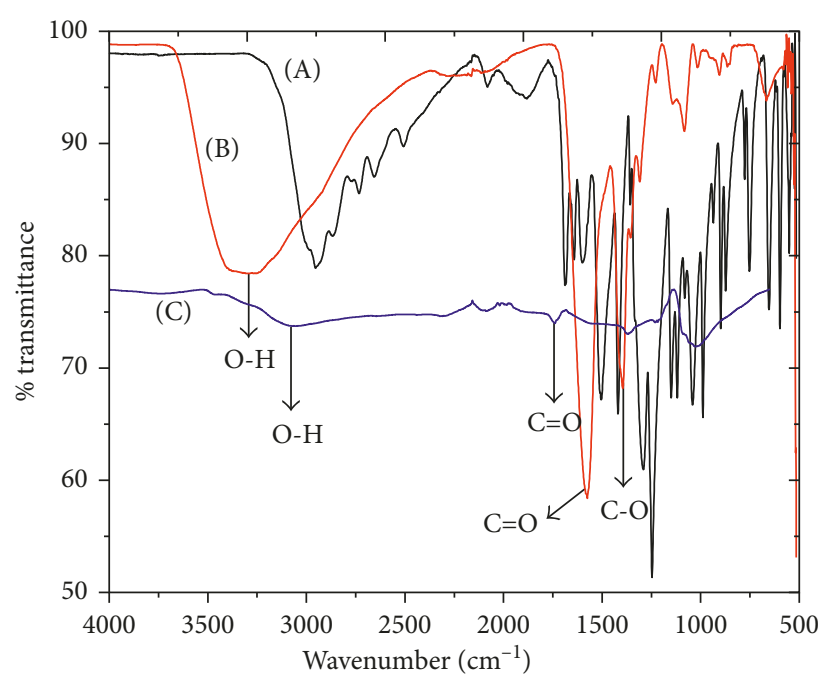

(b)

Figure 1: Infrared spectra of (a) (A) pristine L-alanine, (B) L-alanine-capped ZnS nanoparticles, and (C) L-alanine-capped CuS nanoparticles and (b) (A) pristine L-aspartic acid, (B) L-aspartic acid-capped ZnS nanoparticles, and (C) L-aspartic acid-capped CuS nanoparticles.

and this confirms that the bonding of L-alanine to the surface of the nanoparticles occurred through the basic route of Scheme 1(a).

Figure 1(b) presents the FT-IR spectra of pristine L-aspartic acid- and L-aspartic acid-capped $\mathrm{ZnS}$ and $\mathrm{CuS}$ nanoparticles synthesized at $\mathrm{pH} 10$. The pristine L-aspartic acid spectrum (Figure 1(b), (A)) shows characteristic overlapping bands at 2659 and $2971 \mathrm{~cm}^{-1}$ assigned to $\mathrm{O}-\mathrm{H}$ and $\mathrm{N}-\mathrm{H}$ stretching frequencies, respectively. The FT-IR spectrum of L-aspartic acid-capped ZnS (Figure 1(b), (B)) nanoparticles exhibited a broad peak centred at $3305 \mathrm{~cm}^{-1}$ which was assigned to the $\mathrm{O}-\mathrm{H}$ stretching mode of water. The peak around $1575 \mathrm{~cm}^{-1}$ assigned to the stretching mode of $\mathrm{C}=\mathrm{O}$ was broader than that of pristine $\mathrm{L}$-aspartic acid. The other difference observed was that the overall peaks obtained from the L-aspartic acid-capped $\mathrm{ZnS}$ nanoparticles were slightly blue-shifted compared to those of pristine L-aspartic acid molecule. This is probably because some of the vibrational modes were restricted by attaching to a much heavier transition metal ion $\left(\mathrm{Zn}^{2+}\right)$ on the surface of the nanocrystal lattice [26]. On the other hand, the FT-IR spectrum of L-aspartic acid-capped CuS (Figure 1(b), (C)) nanoparticles exhibited broad peaks centred at $3155 \mathrm{~cm}^{-1}$ and $1643 \mathrm{~cm}^{-1}$, which were assigned to the $\mathrm{O}-\mathrm{H}$ stretching mode of $\mathrm{H}_{2} \mathrm{O}$ and-COO groups. The $\mathrm{C}-\mathrm{O}$ band at $1280 \mathrm{~cm}^{-1}$ appears shifted to lower frequencies as compared to that of pristine L-aspartic acid. Therefore, according to these assignments, carboxylic moieties of the pristine L-aspartic acid molecule were attached to the nanocrystal surface, while the amine moiety remained uncoordinated to impart a hydrophilic nature to the nanoparticles. In general, most of the peaks appearing in the finger print region from 500 to $1000 \mathrm{~cm}^{-1}$ can be assigned to mixed banding modes of $\mathrm{C}-\mathrm{C}$ and $\mathrm{C}-\mathrm{O}$ moieties of the $\mathrm{L}$-aspartic acid-capped $\mathrm{ZnS}$ and $\mathrm{CuS}$ nanoparticles.
3.2. UV-Vis and PL Spectroscopy. The study of optical absorption is important to understand the behaviour of metal chalcogenide nanoparticles. A fundamental property of semiconductor is the band gap which is the energy separation between the filled valence band and the empty conduction band. Optical excitation of electrons across the band gap is strongly allowed, producing a sharp increase in absorption at the wavelength corresponding to the band gap energy $\left(E_{\mathrm{g}}\right)$. This feature in the optical spectrum is known as the optical absorption edge. Amino acid-capped $\mathrm{ZnS}$ and $\mathrm{CuS}$ nanoparticles are optically characterized by UV-Vis and PL spectroscopy. The absorption and emission spectra of L-alanine-capped $\mathrm{ZnS}$ nanoparticles are shown in Figure 2(a). The absorption spectrum is blue-shifted with respect to the bulk material $(345 \mathrm{~nm})$ [27]. A well-resolved excitonic peak was observed around $257 \mathrm{~nm}$ (Figure 2(a), (A)), corresponding to the $1 \mathrm{~S}_{\mathrm{e}}-1 \mathrm{~S}_{\mathrm{h}}$ excitonic transition in the $\mathrm{ZnS}$ nanoparticles [28]. Besides the presence of the peak indicated above, the spectrum also depicts a peak whose absorption band edge appears at approximately $308 \mathrm{~nm}$. The peak is still blue-shifted, signifying the presence of small particles size, which is due to quantum confinement effects. The PL spectrum of L-alanine-capped $\mathrm{ZnS}$ nanoparticles under the excitation wavelength of $300 \mathrm{~nm}$ using distilled water as the solvent is shown in Figure 2(a), (B). The maximum emission peak, appearing at $429 \mathrm{~nm}$, was redshifted from the absorption spectrum.

Figure 2(b) shows the absorption and emission spectra of the as-prepared L-alanine-capped $\mathrm{CuS}$ nanoparticles. copper sulphide is an indirect semiconductor, which leads to typical featureless absorption spectra. The absorption spectrum is blue-shifted as compared to that of the bulk material $(1022 \mathrm{~nm})$ resulting from quantum confinement effects. CuS nanoparticles absorb in the region between 200 and $400 \mathrm{~nm}$ as shown in Figure 2(b), (A). In addition, a broad band 


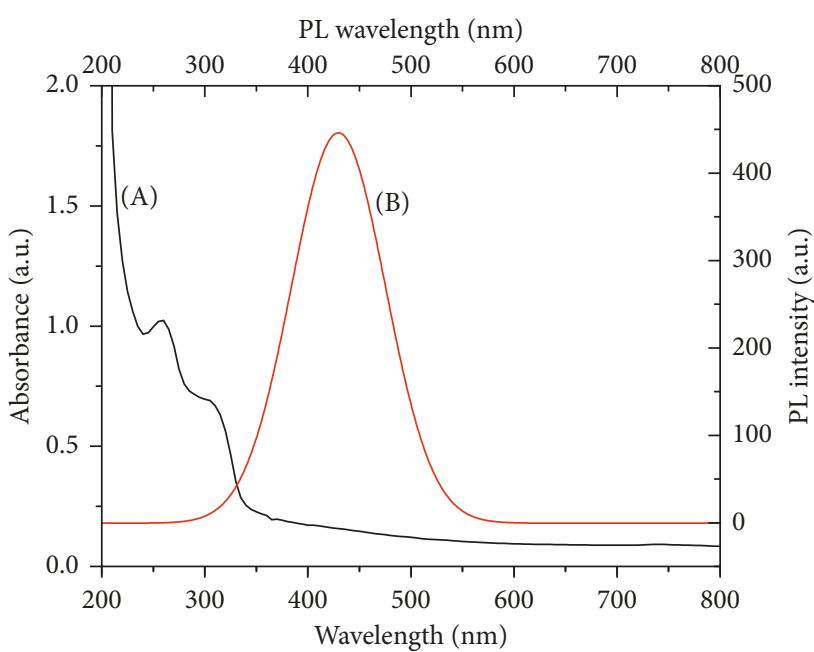

(a)

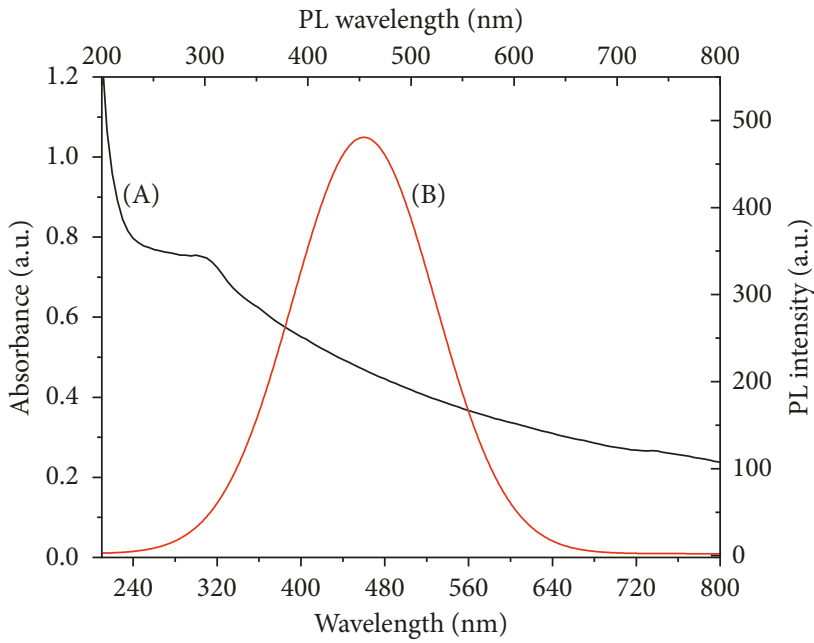

(c)

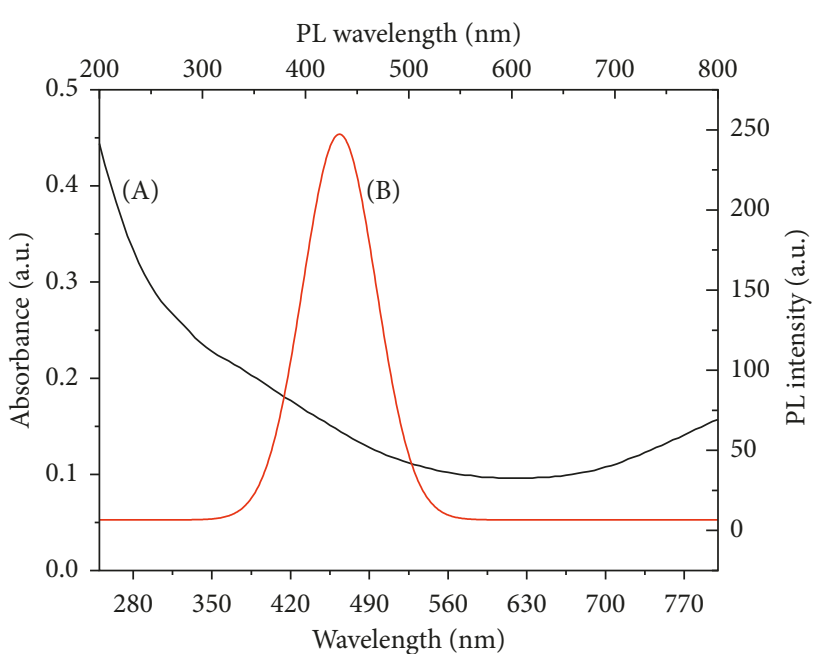

(b)

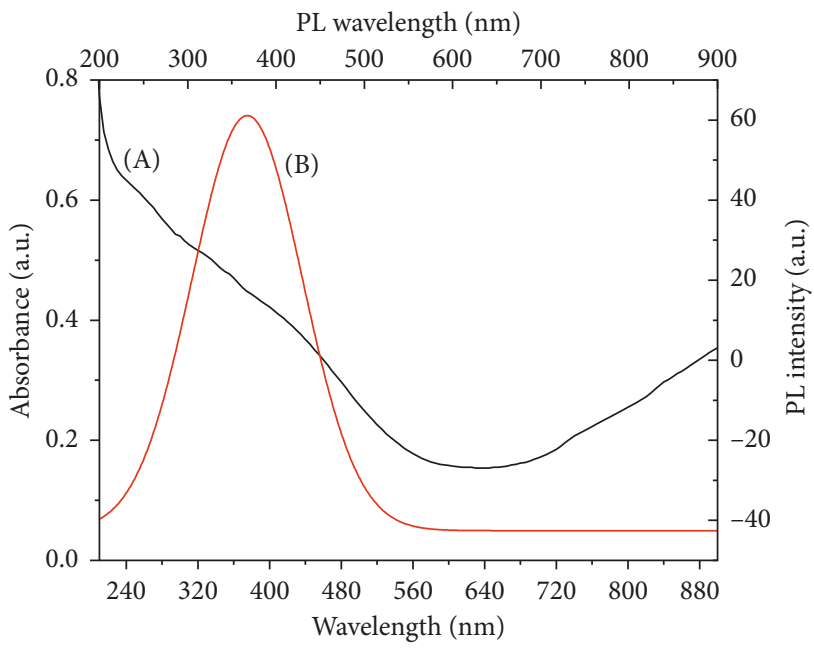

(d)

Figure 2: Absorption (A) and emission (B) spectra of (a) L-alanine-capped ZnS nanoparticles, (b) L-alanine-capped CuS nanoparticles, (c) L-aspartic acid-capped ZnS nanoparticles, and (d) L-aspartic acid-capped CuS nanoparticles.

extending into the near-IR region can be observed, which is characteristic of covellite $\mathrm{CuS}$. It can be concluded that $\mathrm{CuS}$ nanoparticles have a broad absorption in both visible light and near-infrared regions. The emission spectrum, on the other hand, depends on the surface state, size, and surface passivation. The PL spectrum of L-alanine-capped copper sulphide nanoparticles (Figure 2(b), (B)) shows a narrower emission peak under an excitation wavelength of $300 \mathrm{~nm}$ which indicates that the nanoparticles were less polydispersed.

The absorption band edge of $\mathrm{L}$-aspartic acid-capped $\mathrm{ZnS}$ nanoparticles (Figure 2(c), (A)) is blue-shifted to the bulk absorption band edge. The absorption spectrum has large tailing which made it difficult to accurately locate the band edge. The blue shift may be indicative of very small particle sizes. The emission peak (Figure 2(c), (B)) is red-shifted from the respective absorption band edge, and the broadness of the peak suggests that the nanoparticles were polydispersed. The presence of a smooth single peak is indicative of the existence of predominantly single morphology. Like all the absorption spectra above, the spectrum for L-aspartic acid-capped CuS (Figure 2(d), (A)) is also blue-shifted, while a single and smooth PL (Figure 2(d), (B)) peak excited at $275 \mathrm{~nm}$ was observed. The absorption spectrum also showed some nondescriptive absorption in the near-IR region, which is characteristic of covellite CuS.

3.3. XRD Analysis. The powder XRD patterns of $\mathrm{ZnS}$ and $\mathrm{CuS}$ nanoparticles capped with L-alanine and L-aspartic acid are shown in Figures 3(a) and 3(b), respectively. The diffraction peaks of $\mathrm{CuS}$ nanoparticles capped with L-alanine (Figure 3(a), (A)) and L-aspartic acid (Figure 3(a), (B)) at $2 \theta$ values of $32.23^{\circ}, 34.10^{\circ}, 37.05^{\circ}, 45.38^{\circ}, 50.45^{\circ}, 56.24^{\circ}, 62.01^{\circ}$, $67.43^{\circ}$, and $70.09^{\circ}$ correspond to miller indices (101), (102), (103), (105), (106), (110), (108), (202), and (116), respectively. They were closely indexed with the standard peaks of hexagonal phase of CuS (JCPDS no: 06-0464), and the cell 


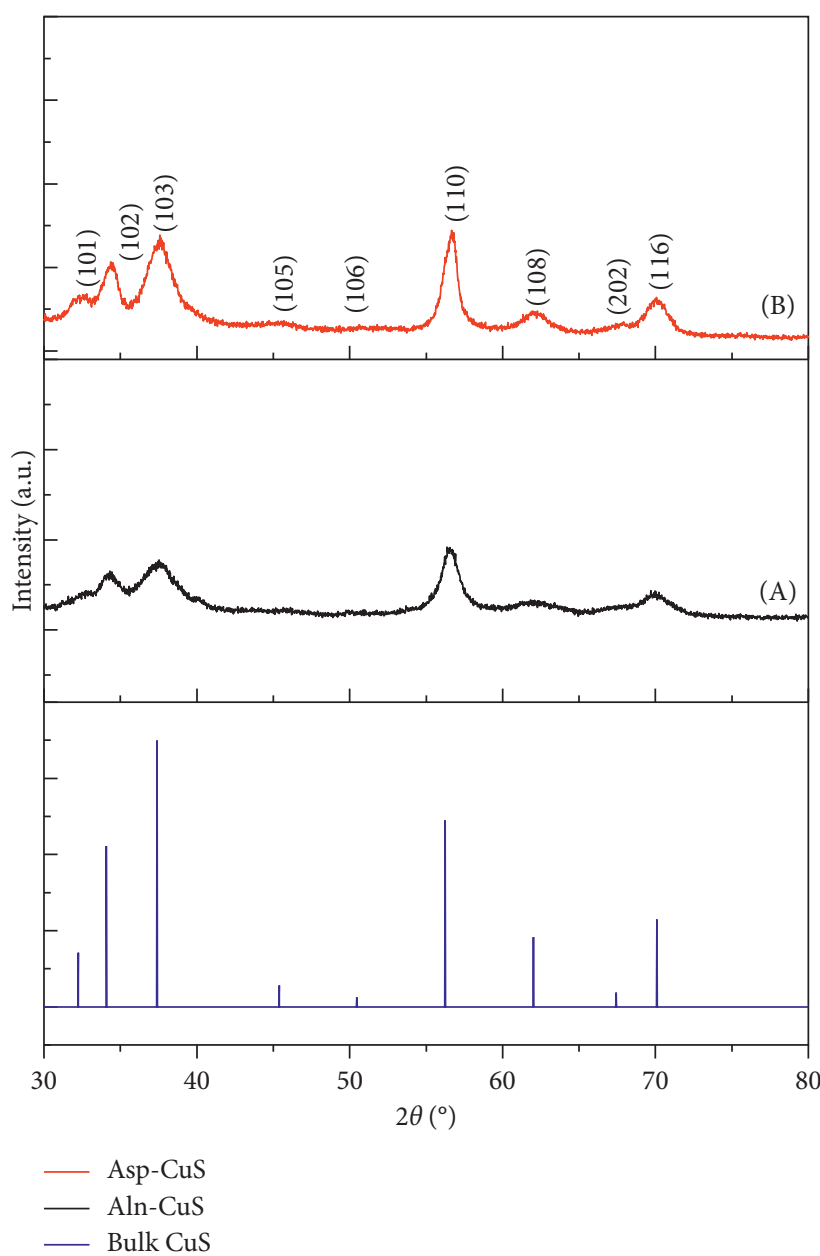

(a)

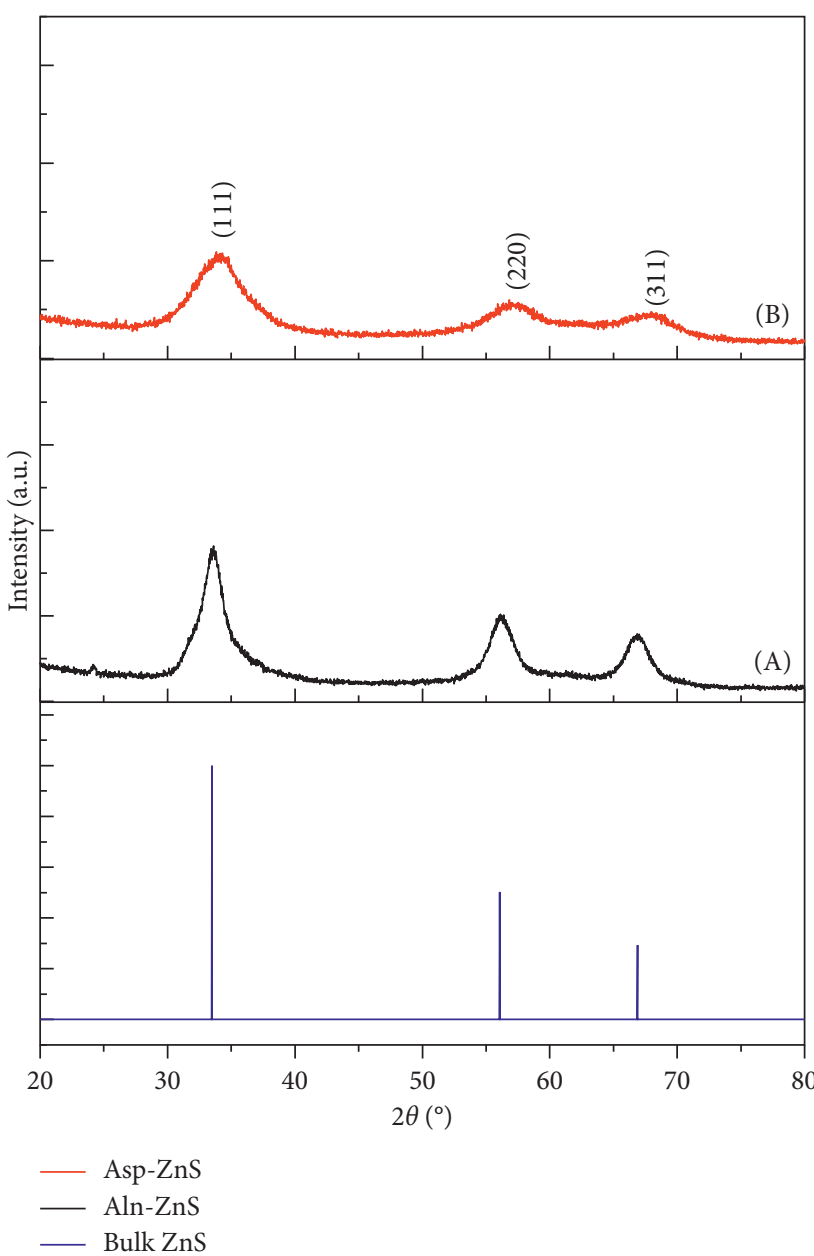

(b)

FIgure 3: Powder X-ray diffraction patterns of (a) (A) L-alanine-capped CuS nanoparticles and (B) L-aspartic acid-capped CuS nanoparticles and (b) (A) L-alanine-capped ZnS nanoparticles and (B) L-aspartic acid-capped ZnS nanoparticles. The bars are from JCPDS standards for hexagonal CuS [06-0464] and cubic ZnS [01-072-4841].

parameters are $a=3.792 \AA$ and $c=16.334 \AA$ [29]. Broadening of the diffraction peaks is clearly seen which confirms small size nanocrystals. No evidence of peaks due to impurities was observed, signifying the purity of the final products. The diffraction peaks of L-alanine-capped CuS (Figure 3(a), (A)) nanoparticles were much broader and less intense than L-aspartic acid-capped $\mathrm{CuS}$ nanoparticles peaks. This was attributed to the formation of less crystalline material with smaller sizes compared to those of L-aspartic acid-capped CuS.

In the case of L-alanine- and L-aspartic acid-capped $\mathrm{ZnS}$ nanoparticles (Figure 3(b), (A and B)), all the broad diffraction peaks obtained at $2 \theta$ values of $33.3,55.8$, and $66.7^{\circ}$ have been assigned to (111), (220), and (311) crystallographic planes of the cubic structure of $\mathrm{ZnS}$, respectively. The diffraction pattern was in good agreement with the JCPDS card of ZnS (JCPDS no: 01-072-4841) [30]. As it was in the case of CuS, no signs of peaks due to impurities were observed in the XRD patterns of ZnS capped with both amino acids. The narrow and high intense peaks for L-alanine-capped $\mathrm{ZnS}$ depicted the highly crystalline nature of the $\mathrm{ZnS}$ nanoparticles compared to those of L-aspartic acidcapped $\mathrm{ZnS}$. The crystalline size of $\mathrm{ZnS}$ nanoparticles was calculated using Scherrer's formula as follows:

$$
d=\frac{k \lambda}{\beta} \cos \theta,
$$

where $d$ is the mean crystalline dimension, $k$ is the crystallite shape constant (0.94), $\lambda$ denotes the wavelength of the X-rays $(\mathrm{Cu} \mathrm{K} \alpha: 1.5406 \mathrm{~A}), \beta$ is the full width at half maximum (FWHM) of the peak in radians, and $\theta$ is the diffraction angle. The average particle size was found to be 3.40 and $1.37 \mathrm{~nm}$ for L-alanine- and L-aspartic acid-capped $\mathrm{ZnS}$ nanoparticles, respectively.

3.4. TEM Analysis. The TEM image of L-alanine-capped $\mathrm{ZnS}$ nanoparticles is shown in Figure 4(a). The particles obtained were composed of agglomerated quasispherical particles. The agglomeration could be attributed to the fact that the particles were very small and that the carboxylic acid group of the L-alanine molecules was dehydrogenized more easily 


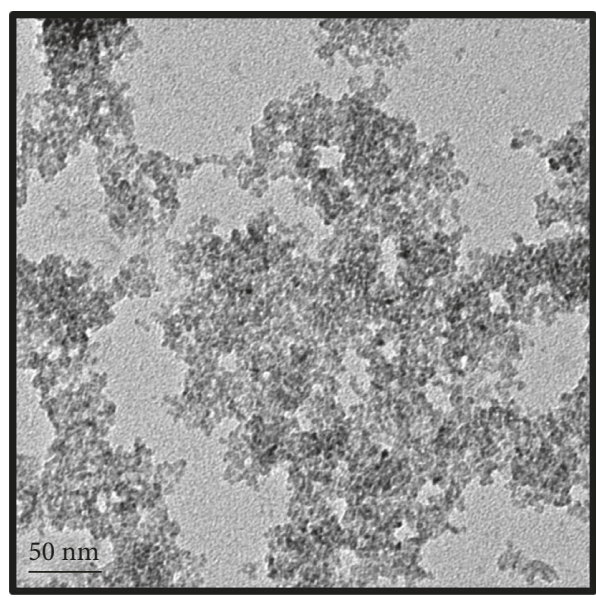

(a)

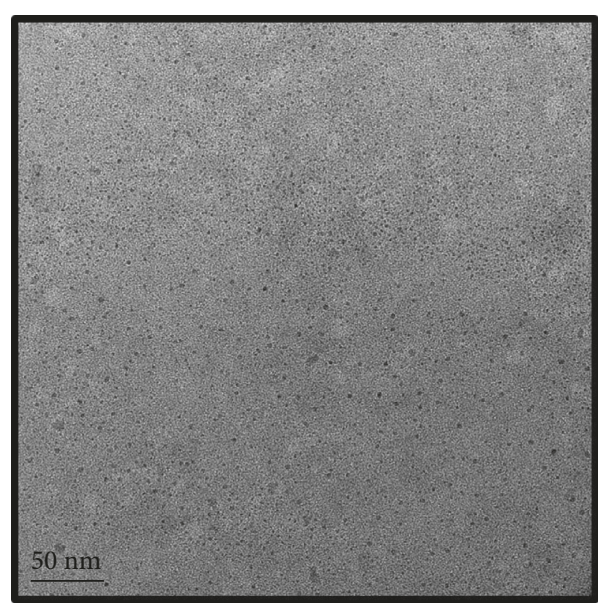

(c)

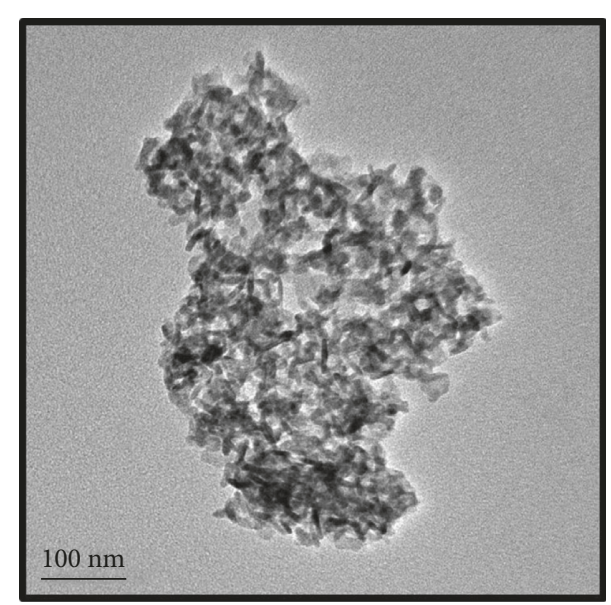

(b)

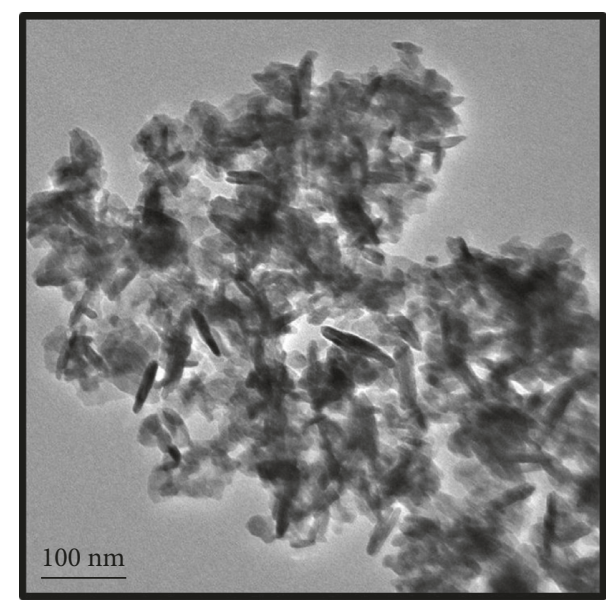

(d)

FIgUre 4: TEM images of (a) L-alanine-capped ZnS, (b) L-alanine-capped CuS, (c) L-aspartic acid-capped ZnS, and (d) L-aspartic acidcapped CuS nanoparticles.

at $\mathrm{pH} 10$ making the surface to become highly charged resulting in the clustering of the nanoparticles. In addition, small particles aggregate to form large particles due to nucleation effect. The average particle diameter was found to be $4.21 \mathrm{~nm}$. The TEM image of L-alanine-capped $\mathrm{CuS}$ nanoparticles (Figure 4(b)) shows that the nanoparticles obtained had mixed morphology with a little bit of spherically shaped particles dominated by rod-shaped particles. It is important to note that the type of the precursor and capping agent influences the reaction pathway as the reaction can proceed under either a thermodynamic or kinetic growth control regime, hence affecting the nanoparticles' morphology. The thermodynamic growth regime is driven by sufficient supply of thermal energy and low flux of monomers (low monomer concentration), yielding an isotropic shaped stable form of nanoparticles such as spheres and cubes. In contrast, under nonequilibrium kinetic conditions with a relatively high flux of monomers, selective anisotropic growth between different crystallographic surfaces is facilitated [31]. The observance of rod-shaped nanoparticles with an aspect ratio of $0.80 \mathrm{~nm}$ confirmed that the reaction was under kinetic control.
The L-aspartic acid-capped $\mathrm{ZnS}$ nanoparticles (Figure 4(c)) were composed of isolated quasispherical particles with no evidence of agglomeration. The small particles are of almost the same size and are well dispersed. Due to the particles being very small, the average particle diameter could not be estimated from the TEM image. Figure 4(d) shows the TEM image of L-aspartic acid-capped CuS nanoparticles. A mixture of amorphous and some signs of distinctive rod-like particles with an aspect ratio of $4.01 \mathrm{~nm}$ were observed.

3.5. Antimicrobial Activity. The results of antimicrobial activity (Table 1) indicate that copper sulphide-capped nanoparticles were more effective against the bacteria than zinc nanoparticles. This can be attributed to the ability of copper to release $\mathrm{Cu}^{2+}$ ions which can penetrate and disrupt the cell membrane and biochemical pathway by chelating cellular enzymes and DNA damage [32]. S. aureus was the most susceptible microorganism with the MIC of $0.05 \mathrm{mg} / \mathrm{mL}$ for uncapped-CuS while $P$. aeruginosa and C. neoformans were the least susceptible with MIC of 
TABLE 1: Minimum inhibitory concentration (MIC) of amino acid-capped copper and zinc sulphide nanoparticles (mg/mL).

\begin{tabular}{|c|c|c|c|c|c|c|}
\hline \multirow{3}{*}{ Bacterial strains } & \multicolumn{6}{|c|}{ Nanoparticles } \\
\hline & \multicolumn{4}{|c|}{ Copper } & \multicolumn{2}{|c|}{ Zinc } \\
\hline & Unc-CuS & Aln-CuS & Asp-CuS & Unc-ZnS & Aln-ZnS & Asp-ZnS \\
\hline S. aureus & $<0.05$ & 0.1 & 0.1 & 0.20 & 3.125 & 6.25 \\
\hline E. faecalis & 0.39 & 0.78 & 0.78 & 1.56 & 25 & 25 \\
\hline K. pnuemoniae & 0.195 & 0.39 & 0.39 & 0.40 & 25 & 25 \\
\hline$P$. aeruginosa & 3.125 & 1.56 & 1.56 & 0.78 & 0.78 & 0.78 \\
\hline C. albicans & 1.56 & 1.56 & 0.78 & 0.2 & 6.25 & 25 \\
\hline C. neoformans & 0.39 & 3.125 & 0.391 & 1.56 & 12.5 & 6.25 \\
\hline
\end{tabular}

Neomycin MIC $(\mu \mathrm{g} / \mathrm{mL})$ : S. aureus: <0.4; E. faecalis: $6.25 ;$ K. pnuemoniae: 12.5 ; P. aeruginos: <0.4; C. albicans: nd; C. neoformans: 3.125.

$3.125 \mathrm{mg} / \mathrm{mL}$ for both uncapped-CuS and Aln-CuS. In another study, S. aureus was found to be most susceptible to zinc ferrite nanoparticles as previously reported by Mandal et al. [33]. The copper-capped nanoparticles seemed to be more effective against Gram-positive compared to Gramnegative bacteria and fungi. This is attributed to the differences in the structure of their cell walls. The cell wall of Gram-negative microorganisms is comprised of a thin peptidoglycan layer and an outer lipopolysaccharide layer, whereas the cell wall of Gram-positive microorganisms is composed of a thick peptidoglycan layer but does not have the outer lipopolysaccharide.

\section{Conclusions}

The functionalized amino acid-capped $\mathrm{ZnS}$ and $\mathrm{CuS}$ nanoparticles with a single crystal phase were synthesized successfully in an aqueous medium, through a simple colloidal route. FT-IR analysis confirmed the binding of amino acid molecules to the surface of the nanoparticles. All absorption spectra were blue-shifted from their bulk material due to quantum confinement effects. The XRD analysis revealed the cubic zinc blende structure of $\mathrm{ZnS}$ nanoparticles with no evidence of impurities, whereas $\mathrm{CuS}$ nanoparticles were of a hexagonal phase (covellite). The TEM images showed that the amino acid-capped $\mathrm{ZnS}$ nanoparticles followed thermodynamic growth regime and were composed of agglomerated and isolated quasispherical particles, while amino acid-capped $\mathrm{CuS}$ nanoparticles followed kinetic growth regime with mixed morphology.

\section{Data Availability}

The data used to support the findings of this study are included within the article.

\section{Conflicts of Interest}

The authors declare that they have no conflicts of interest.

\section{Acknowledgments}

The authors would like to acknowledge the National Research Foundation (NRF-South Africa) under the CSUR Grant UID: 97064, the Vaal University of Technology for financial support and Mintek-NIC for the use of specialised equipment. The project was funded by the National Research Foundation (RSA) (CSUR grant UID: 97064).

\section{References}

[1] X. Peng, L. Manna, W. Yang et al., "Shape control of $\{\mathrm{CdSe}\}$ nanocrystals," Nature, vol. 404, pp. 59-61, 2000.

[2] J. P. Borah, J. Barman, and K. C. Sarma, "Structural and optical properties of $\mathrm{ZnS}$ nanoparticles," Chalcogenide Letters, vol. 5, pp. 201-208, 2008.

[3] U. S. Senapati, D. K. Jha, and D. Sarkar, "Green synthesis and characterization of ZnS nanoparticles," Research Journal of Physical Sciences, vol. 1, pp. 1-6, 2013.

[4] C. A. Antonyraj, J. Jeong, B. Kima et al., "Selective oxidation of HMF to DFF using Ru/ $\gamma$-alumina catalyst in moderate boiling solvents toward industrial production," Journal of Industrial and Engineering Chemistry, vol. 19, no. 3, pp. 1056-1059, 2013.

[5] N. Frances, A. P. Nikolay, J. F. B. Michael, G. Tim, and A. M. Paul, "Novel one-pot synthesis and characterization of bioactive thiol-silicate nanoparticles for biocatalytic and biosensor applications," Nanotechnology, vol. 20, no. 5, p. 055612, 2009.

[6] X. Luo, A. Morrin, A. J. Killard, and M. R. Smyth, "Application of nanoparticles in electrochemical sensors and biosensors," Electroanalysis, vol. 18, no. 4, pp. 319-326, 2006.

[7] S. K. Murthy, "Nanoparticles in modern medicine: state of the art and future challenges," International Journal of Nanomedicine, vol. 2, pp. 129-141, 2007.

[8] S. S. Staniland, "Magnetosomes: bacterial biosynthesis of magnetic nanoparticles and potential biomedical applications," in Nanotechnologies for the Life Sciences, Wiley-VCH Verlag GmbH \& Co. KGaA, Weinheim, Germany, 2007.

[9] Z. Q. Wen, G. Li, and D. Ren, "Detection of trace melamine in raw materials used for protein pharmaceutical manufacturing using surface-enhanced Raman spectroscopy (SERS) with gold nanoparticles," Applied Spectroscopy, vol. 65, no. 5, pp. 514-521, 2011.

[10] Y. Xia, H. Yang, and C. T. Campbell, "Nanoparticles for catalysis," Accounts of Chemical Research, vol. 46, no. 8, pp. 1671-1672, 2013.

[11] A. Phuruangrat, P. Thoonchalong, S. Thongtem, and T. Thongtem, "Synthesis of CuS with different morphologies by refluxing method: nanopaticles in clusters and nanoflakes in sponge-like clusters," Chalcogenide Letters, vol. 9, pp. 421-426, 2012.

[12] M. C. Brelle, J. C. Mcnulty, and R. K. Mehra, "Synthesis and characterization of $\mathrm{Cu}_{\mathrm{x}} \mathrm{S}$ nanoparticles. Nature of the infrared band and charge-carrier dynamics," Pure and Applied Chemistry, vol. 72, no. 1-2, pp. 101-117, 2000. 
[13] A. Singh, R. Manivannan, and S. N. Victoria, "Simple one-pot sonochemical synthesis of copper sulphide nanoparticles for solar cell applications," Arabian Journal of Chemistry, vol. 8, pp. 1-9, 2015.

[14] N. K. Abbas, K. T. Al-Rasoul, and Z. J. Shanan, "New method of preparation $\mathrm{ZnS}$ nanosize at low $\mathrm{pH}$," International Journal of Electrochemical Science, vol. 8, pp. 3049-3056, 2013.

[15] N. Revaprasadu, A. M. Malik, and P. O'Brien, "Synthesis of TOPO-capped nanocrystals of copper sulphide from a singlesource precursor, $\left[\mathrm{Cu}\left(\mathrm{S}_{2} \mathrm{CNMe}(\mathrm{n} \mathrm{Hex})\right)_{2}\right]$," South African Journal of Chemistry, vol. 57, pp. 40-43, 2004.

[16] C. Liu, Y. Ji, and T. Tan, "One-pot hydrothermal synthesis of water-dispersible $\mathrm{ZnS}$ quantum dots modified with mercaptoacetic acid," Journal of Alloys and Compounds, vol. 570, pp. 23-27, 2012.

[17] A. Ahmad, P. Mukherjee, D. Mandal et al., "Enzyme mediated extracellular synthesis of CdS nanoparticles by the fungus, Fusarium oxysporum," Journal of American Chemistrey Scociety, vol. 124, no. 41, pp. 12108-12109, 2002.

[18] A. Zielińska-Jurek, J. Reszczyńska, E. Grabowska, and A. Zaleska, "Nanoparticles preparation using microemulsion systems," in Microemulsions-An Introduction to Properties and Applications, R. Najjar, Ed., InTech, London, UK, 2012, http://www.intechopen.com/books/microemulsions-an-introduction-to-properties-and-applications/nanoparticles-preparation-using-microemulsion-systems.

[19] H. Jeon, T. Sugiyama, H. Masuhara, and T. Asahi, "Study on electrophoretic deposition of size-controlled quinacridone nanoparticles," Journal of Physical Chemistry, vol. 111, no. 40, pp. 14658-14663, 2007.

[20] B. Meenatchi, V. Renuga, and A. Manikanda, "Sizecontrolled synthesis of chalcogen and chalcogenide nanoparticles using protic ionic liquids with imidazolium cation," Korean Journal of Chemical Engineering, vol. 33, no. 3, pp. 934-944, 2016.

[21] D. C. Onwudiwe, A. D. Mohammed, C. A. Strydom, D. A. Young, and A. Jordaan, "Colloidal synthesis of monodispersed ZnS and CdS nanocrystals from novel zinc and cadmium complexes," Superlattices and Microstructures, vol. 70, pp. 98-108, 2014.

[22] C. Tan, Y. Zhu, R. Lu et al., "Synthesis of copper sulfide nanotube in the hydrogel system," Materials Chemistry and Physics, vol. 91, no. 1, pp. 44-47, 2005.

[23] J. N. Eloff, "A sensitive and quick microplate method to determine the minimal inhibitory concentration of plant extracts for bacteria," Planta Medica, vol. 64, no. 8, pp. 711$713,1998$.

[24] B. Ncube, J. F. Finnie, and J. V. Staden, "Seasonal variation in antimicrobial and phytochemical properties of frequently used medicinal bulbous plants from South Africa," South African Journal of Botany, vol. 77, no. 2, pp. 387-396, 2011.

[25] P. Masoko, J. Picard, and J. N. Eloff, "The antifungal activity of twenty-four southern African Combretum species (Combretaceae)," South African Journal of Botany, vol. 73, no. 2, pp. 173-183, 2007.

[26] J. Heo and C. Hwang, "Application of L-Aspartic acid-capped ZnS: Mn colloidal nanocrystals as a photosensor for the detection of copper(II) ions in aqueous solution," Nanometerials, vol. 6, no. 5, pp. 82-87, 2016.

[27] S. K. Maji, A. K. D. Dutta, D. N. Srivastava, P. Paul, A. Mondal, and B. Adhikary, "Effective photocatalytic degradation of organic pollutant by $\mathrm{ZnS}$ nanocrystals synthesized via thermal decomposition of single-source precursor," Polyhedron, vol. 30, no. 15, pp. 2493-2498, 2011.
[28] L. Wang, X. T. Tao, J. X. Yang, Y. Ren, Z. Liu, and M. H. Jiang, "Preparation and characterization of the $\mathrm{ZnS}$ nanospheres with narrow size distribution," Optical Materials, vol. 28, no. 8-9, pp. 1080-1083, 2006.

[29] M. Saranya, C. Santhosh, R. Ramachandran et al., "Hydrothermal growth of $\mathrm{CuS}$ nanostructures and its photocatalytic properties," Powder Technology, vol. 252, pp. 25-32, 2014.

[30] A. A. Othman, M. A. Osman, and M. H. Wahdan, "Thermal annealing and UV induced effects on the structural and optical properties of capping free $\mathrm{ZnS}$ nanoparticles synthesized by co-precipitation method," International Journal of General Engineering and Technology, vol. 3, pp. 9-16, 2014.

[31] N. Moloto, N. Revaprasadu, P. L. Musetha, and M. J. Moloto, "The effect of precursor concentration, temperature and capping group on the morphology of CdS nanoparticles," Journal of Nanoscience and Nanotechnology, vol. 9, no. 8, pp. 4760-4766, 2009.

[32] U. Bogdanovic, V. Lazic, V. Vodnik, M. Budimir, and Z. Markovic, "Copper nanoparticles with high antimicrobial activity," Materials Letters, vol. 128, pp. 75-78, 2014.

[33] S. Mandal, S. Natarajan, A. Tamilselvi, and S. Mayadevi, "Photocatalytic and antimicrobial activities of zinc ferrite nanoparticles synthesize through soft chemical route: a magnetically recyclable catalyst for water/waste water," Journal of Environmental Chemical Engineering, vol. 4, no. 3, pp. 2706-2712, 2016. 


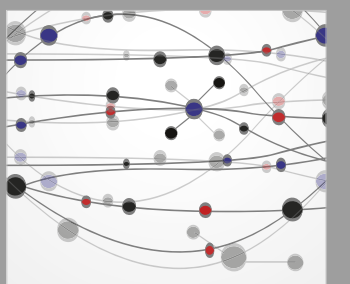

The Scientific World Journal
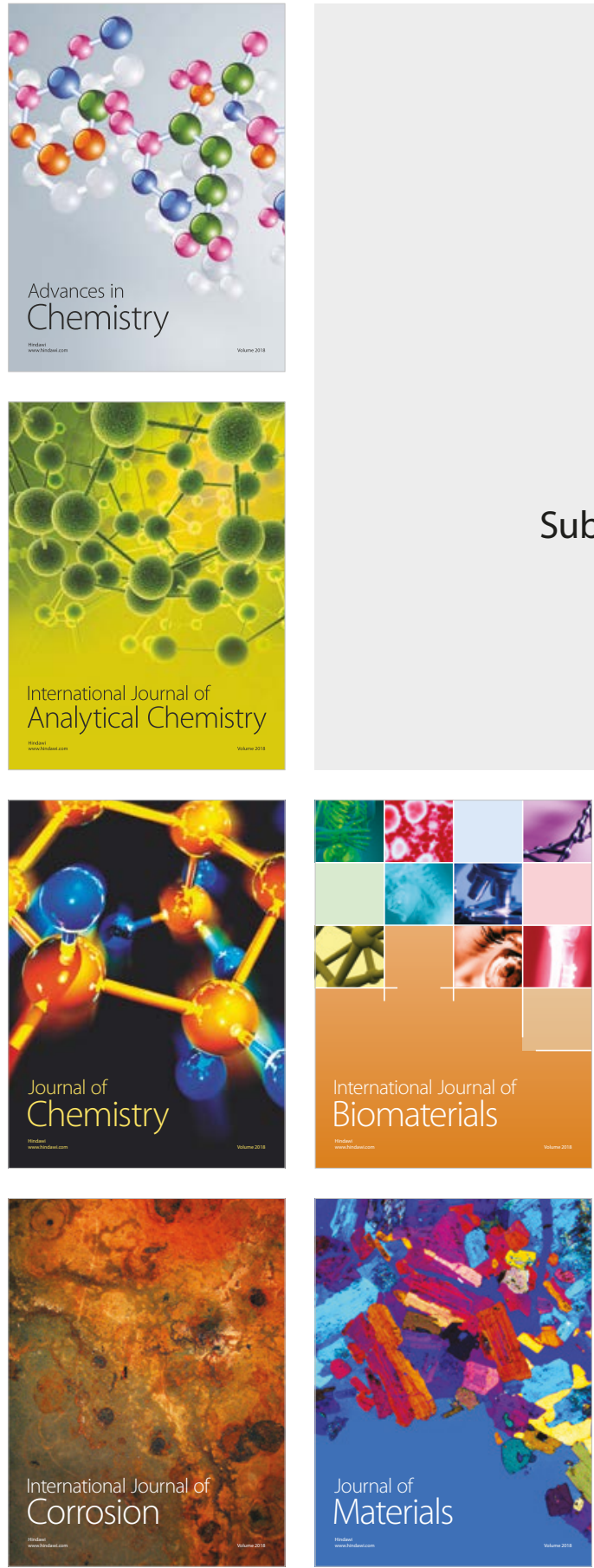

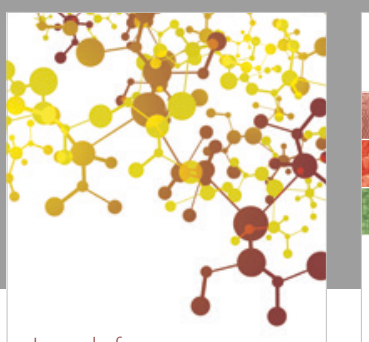

Journal of

Applied Chemistry
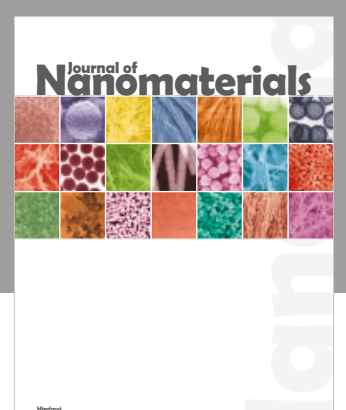

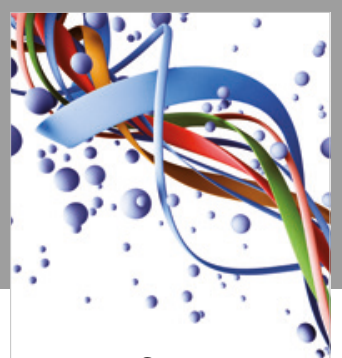

Scientifica

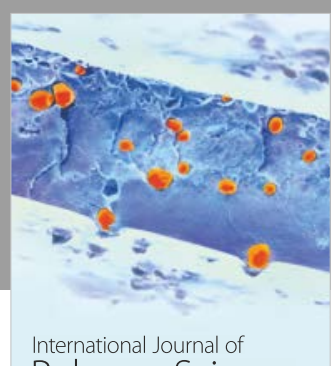

Polymer Science

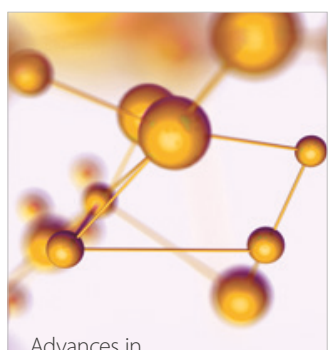

Physical Chemistry
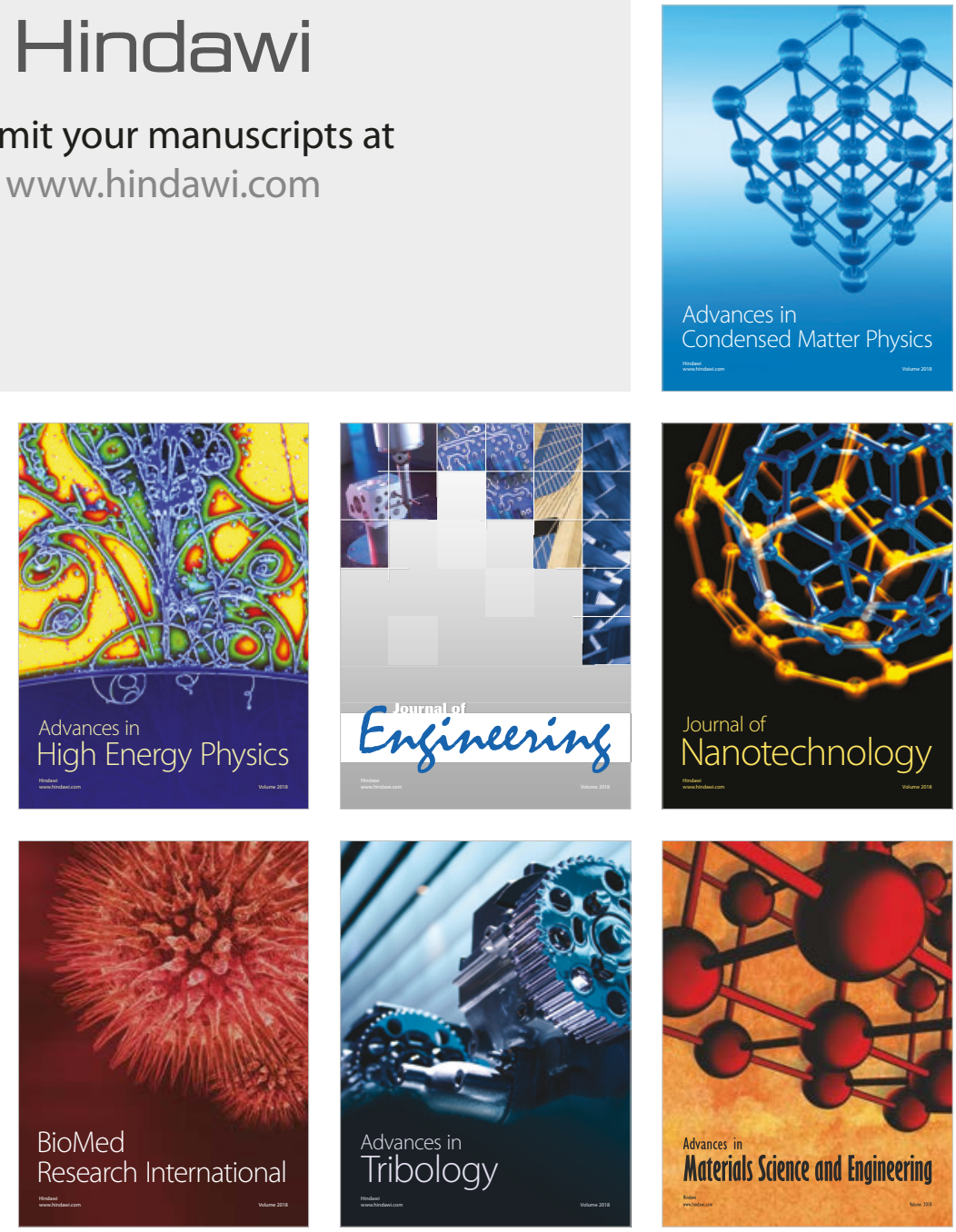